2 Davies S, Nolan M, Brown J, Wilson F. Dignity on the ward: promoting excellence in care-Good practice in acute hospital care for older people. London: Help the Aged and the Orders of St John Trust, 2000.

3 General Medical Council. Good medical practice. London: GMC, 1998.

4 Department of Health. National Service Framework for Older People. London: DH, 2001. www.doh.gov.uk/nsf/olderpeople/ index.htm

5 British Medical Association and Law Society. Assessment of mental capacity. London: BMA, 1995.

6 Lord Chancellor's Department. Making decisions. Cm 4465. 1999. www.open. gov.uk/lcd/family/mdecisions

7 Making Decisions Alliance. www.makingdecisions.org.uk

8 Department of Health. Reference guide to consent for examination or treatment. London: DH, 2001. www.doh.gov.uk/ consent

9 Sayers GM, Barratt D, Gothard C, Onnie $C$ et al. The value of taking an 'ethics history'. J Med Ethics 2001;27:114-7.

10 General Medical Council. Confidentiality: protecting and providing information. London: GMC, 2001.

11 Slowther AM. The case of Ms B and the 'right to die'. J Med Ethics 2002;28:243.

12 All England Law Reports. Airedale NHS Trust $v$ Bland, (1993) I, 821-896.

13 General Medical Council. Withholding and withdrawing life-prolonging treatments: good practice in decision-making. London: GMC, 2002.

14 Pennington C. To PEG or not to PEG. Review. Clin Med 2002;2:230-5.

15 British Medical Association, Resuscitation Council and Royal College of Nursing. Decisions relating to cardiopulmonary resuscitation. London: BMA, RC, RCN, March 2001. web.bma.org.uk/cpr

16 O'Keefe ST. Development and implementation of resuscitation guidelines: a personal experience. Age Ageing 2001;30:19-25.

17 Morgan R, King D, Prajapati C, Rowe J. Views of elderly patients and their relatives on cardiopulmonary resuscitation. BMJ 1994;308:1677-8.

\section{How far to}

\section{investigate older}

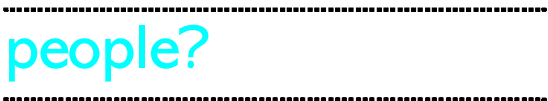

B J Adler MB MRCP, Senior House Officer

David J Stott MB MD FRCP (Glas, Ed), Professor of Geriatric Medicine

Academic Section of Geriatric Medicine, Glasgow Royal Infirmary

Clin Med 2003;3:418-22

When assessing older people, clinicians are often faced with difficult decisions in deciding how far to investigate them. There are now guidelines for the investigation of most common clinical problems, but these often fail to address common situations of comorbidity, disability and cognitive impairment in older people.

The principle of assessing potential benefits and risks before embarking upon a medical investigation is important for patients of all ages and all medical specialties. However, decisions in older patients can involve many different factors; this complexity poses a considerable challenge. This article examines key issues that should be considered when deciding how far investigation should be pursued in an older patient, illustrating these processes of assessment and decision-making with common clinical problems in three different patient case scenarios.

\section{Identifying key factors that may influence a decision to investigate}

\section{Major physical comorbidity}

Multiple pathology becomes increasingly common with advancing age, with an increase in many chronic diseases. ${ }^{1}$ When assessing an older patient it is therefore more appropriate to use a process of identification of problems and problem solving rather than to seek a single unifying diagnosis to explain all the patient's symptoms and clinical signs. People over 70 years have an average of five medical complaints. ${ }^{2}$ Conditions that become particularly common include:

- ischaemic vascular disease

- hypertension

- diabetes mellitus

- osteoarthritis

- visual impairment, and

- deafness.

Symptoms of ischaemic heart disease (angina or previous myocardial infarction) are present in $20-30 \%$ of people over 65 years of age and $5-10 \%$ have a history of stroke. ${ }^{1}$ Faced with an older patient with multiple comorbidities, the clinician has to make a judgement as to which of these are most likely to be adversely affecting quality of life (QoL) and which will be the limiting factor in determining life expectancy. Effective prioritisation ensures that investigations are selected that are most likely to give useful prognostic information or lead to a change in management.

\section{Cognitive impairment}

The prevalence of chronic cognitive impairment increases with advancing age. This includes mild problems (present in ca $16 \%$ of those over 65 years) which do not fulfil standard criteria for diagnosis of dementia. ${ }^{2}$ This syndrome is now known as 'mild cognitive impairment'. Such subjects are at high risk of progressive cognitive decline.

About $8 \%$ of over 65 s have dementia, rising to $40 \%$ in people over $90 .^{3}$ Dementia is associated with a high mortality, with a mean survival of approximately seven years from the time of diagnosis in Alzheimer's disease patients. ${ }^{4}$ It is also a major cause of impaired QoL. However, the boundary between minimal cognitive impairment and dementia is somewhat arbitrary and difficult to define. Different diagnostic criteria for dementia mean that the proportion of patients given the label of dementia varies up to tenfold. ${ }^{5}$ Great caution should therefore be exerted in the use of the term 'dementia' and it is often preferable to use the label of 'chronic cognitive impairment'. 
The incidence of acute confusional states or delirium also rises dramatically in older patients, occurring in 15-20\% of hospital patients over the age of $65 .^{6}$ Doctors fail to detect up to $50 \%$ of cases of acute or chronic confusion, ${ }^{7}$ although performance is improved with training and routine use of simple cognitive function tests. ${ }^{6}$

Patients with cognitive impairment, acute or chronic, will often be unable to give informed consent to investigation. This becomes particularly important if invasive investigation such as endoscopy is contemplated. Therefore, in planning investigations it is important to identify older patients with cognitive impairment and to clarify whether it is acute, chronic or acute-on-chronic. This requires interview of a surrogate (usually a carer or relative) to determine the time course of the cognitive impairment, and routine use of standard questionnaires such as the Abbreviated Mental Test $(\mathrm{AMT})^{8}$ or the Mini-Mental State Examination. ${ }^{9}$

\section{Physical disability}

Severe physical disability becomes increasingly common with ageing - it is present in more than $10 \%$ of patients over the age of $80 .{ }^{10}$ Identification of disability should trigger a process of identifying modifiable contributors, including chronic disease states, environmental influences and physical inactivity. Marked disability can make some investigations (eg treadmill exercise stress test) difficult or impossible. Simple and quick questionnaires such as the Barthel index ${ }^{11}$ can be used to assess mobility, self-care and continence (basic activities of daily living). This type of disability assessment should be routine in all frail older patients.

\section{The patient's views and wishes}

The patient's views are imperative in considering whether to pursue investigation. In general, older people are more concerned about symptom control and QoL than life expectancy. Attitudes vary greatly, but for many older people life with severe physical disability or dementia is rated as an outcome worse than death. ${ }^{12,13}$ Where patients are unable to communicate their wishes or are unable to give informed consent to investigation, the views of the next-ofkin need to be sought. Legislation varies in different countries (including the different parts of the UK); clinicians must be aware of the correct legal process for their own countries. The use of advance directives is becoming more widespread; if one is available, it should be used to plan care in accordance with the patient's wishes.

There are occasions when the patient's views are based on inappropriate or inaccurate assumptions, such as an unduly negative attitude to likely life expectancy or focusing on one small specific problem or issue that is much less important than a comorbid condition. The physician should try gently to persuade the patient to accept the most rational plan (Fig 1).

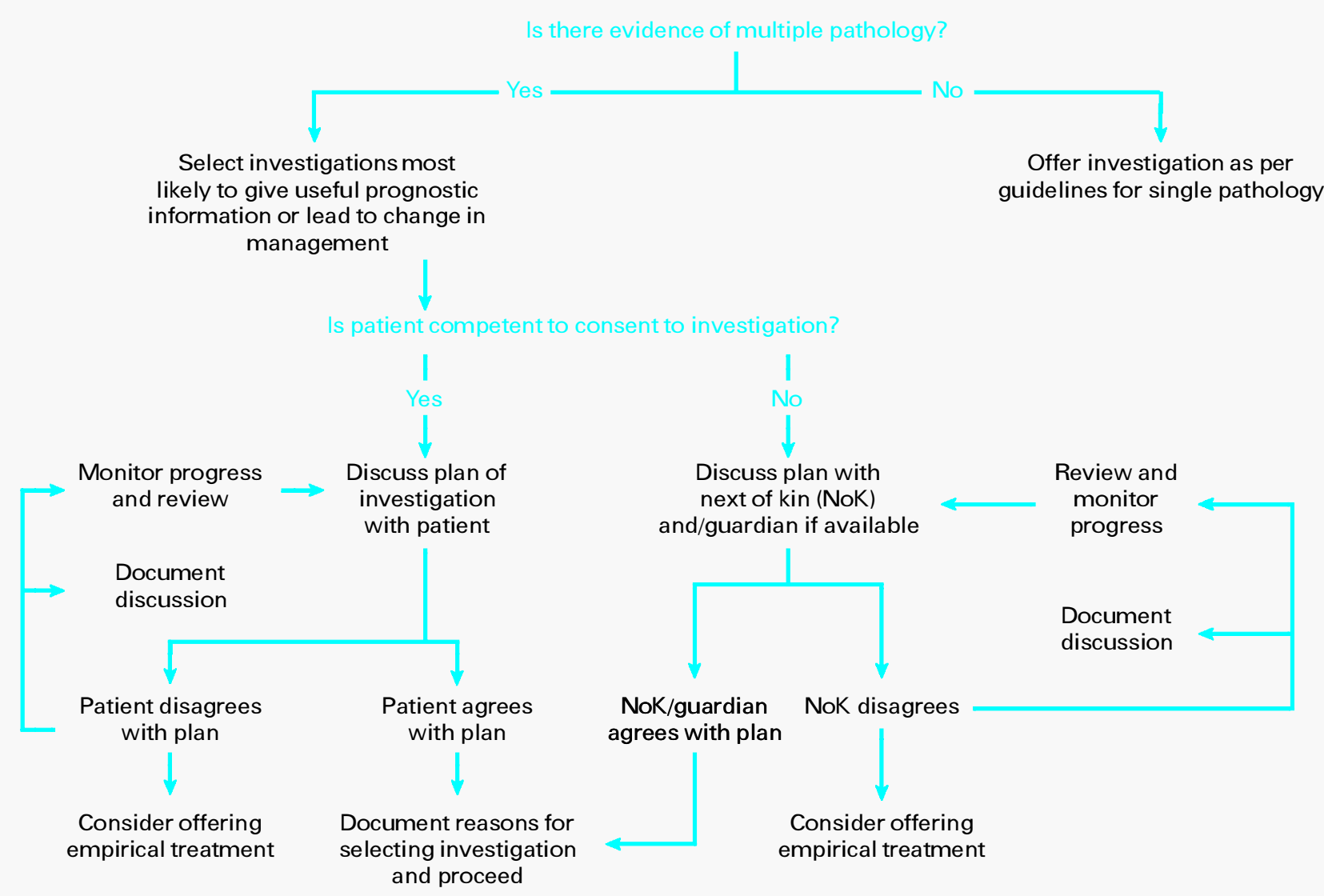

Fig 1. Algorithm for decision-making in investigating the elderly patient (NoK = next-of-kin). 


\section{The potential benefits and risks of investigation}

When requesting an investigation, it is important for the clinician to be clear about the reasons for the request and to consider what action will be taken if the investigation confirms a suspected diagnosis. A principle often applied is that an investigation should not be requested unless its result has the potential to alter a patient's management. Ideally, a test will be chosen that will identify a disease process and enable selection of a treatment that will lead to a cure. In reality, this is not often the case, and management options may be primarily limited to symptom control, although many interventions in older patients have been shown to prolong survival.

Investigations can also be important in defining likely prognosis. Even if treatment is not affected, this information can help patients and their relatives to plan home support services and placement. Firmly establishing some diagnoses (such as cancer) opens up wider opportunities for support, including enhanced financial allowances, hospice care and cancer outreach services.

Invasive investigations are associated with risks which have to be balanced against the likely benefit to the patient. Benefit from investigation is unlikely when the problem being pursued does not greatly affect QoL or likely life expectancy; in this circumstance, investigation will only expose the patient to risk without any likely gain.

\section{Case scenarios}

\section{Case 1}

\section{Medical history and examination}

An 83-year-old man is admitted to hospital with acute-onset dysphasia, rightsided hemiplegia and right homonymous hemianopia. A computed tomography (CT) brain scan shows a left middle cerebral artery territory infarction. Routine blood tests reveal anaemia with haemoglobin of $8.2 \mathrm{~g} / \mathrm{dl}$ and a low serum ferritin of $10 \mathrm{ng} / \mathrm{ml}$.

Question: should he undergo gastrointestinal investigation (upper gastrointestinal endoscopy and colonoscopy) seeking a source of blood loss?

\section{Opinion}

This man's primary problem is his stroke. He has a total anterior cerebral syndrome, a potentially life-threatening condition. If he survives, the risk of severe residual disability is high. ${ }^{14}$

Upper gastrointestinal (GI) endoscopy and colonoscopy are the standard inves-

\section{Key Points}

For an older patient with multiple comorbidities, investigations should be focused on those problems or conditions that adversely affect quality of life and/or are likely to limit life expectancy

Key factors that influence the decision whether to investigate an older patient include comorbid disease, likely life expectancy, cognitive status, disability and the patient's wishes

If a decision is taken not to investigate, the reasons behind this should be clearly documented

Cognitive impairment is common in older patients and often missed in medical assessments. Detection is improved if standardised questionnaires such as the Abbreviated Mental Test are used routinely

Disability is common in older patients but often poorly documented in case records. The routine use of simple questionnaires such as the Barthel Index (which records aspects of mobility, basic self-care and continence) is recommended

KEY WORDS: cognition, comorbidity, disability, older patients, medical investigation

tigations to find a source of chronic blood loss causing iron deficiency anaemia. ${ }^{15}$ However, proceeding early to these investigations may be hazardous and the risks outweigh the benefits. Upper GI endoscopy puts the patient at risk of hypoxia, which may increase the extent of his cerebral damage. Colonoscopy might be impracticable due to the patient's reduced mobility. His dysphasia is likely to prevent him understanding the reasons for the GI investigations, and he may be unable to give informed consent.

Plan

Investigation of the anaemia should be delayed until the outcome of the stroke becomes clear. A pragmatic initial management plan would be to avoid antiplatelet drugs, give iron supplements and observe the full blood count. If he makes a good recovery from his stroke, this is the time to discuss GI investigations with him; if he is willing, these investigations could be done about 4-6 weeks after the stroke. Not finding an obvious source of bleeding would allow cautious introduction of antiplatelet agents with the aim of reducing the risk of future stroke or myocardial infarction. Identification of a tumour such as a colonic carcinoma would lead to consideration of surgery. The diagnosis of a malignancy that could not be treated might well alter the placement and general support offered to such a patient.

If he does not make a good recovery and is left with residual severe disability after his stroke, this should remain the priority for care management. GI investigations would not normally be pursued unless he has continued blood loss requiring repeated blood transfusion.

\section{Case 2}

\section{Medical history and examination}

A 76-year-old woman is admitted with a three-month history of anterior chest discomfort occurring on minor exertion and relieved by rest. The ECG shows anterolateral ST-T depression. She has a 
three-year history of Parkinson's disease and osteoarthritis of both hips. Before her current symptoms she could walk 10-15 yards with a wheeled Zimmer frame.

Question: would you offer a cardiac stress test to this woman?

\section{Opinion}

This woman has typical symptoms of angina pectoris. She has comorbidity in the form of Parkinson's disease and osteoarthritis, but the primary factor limiting her mobility at present is angina and the major risk of death is from ischaemic heart disease. Older patients with angina tend to have more severe coronary artery disease than their younger counterparts and are at increased risk of death. However, older people are often denied access to cardiac investigation and coronary revascularisation. ${ }^{16}$

\section{Plan}

In a patient with such cardiac symptoms it would be usual to perform a stress test to define the risk more precisely and identify whether coronary angiography and possible revascularisation (percutaneous coronary angioplasty or coronary artery bypass grafting) are required. ${ }^{17}$ Bicycle or treadmill testing is likely to be difficult in this patient; pharmacological stress testing with dipyridamole, dobutamine or adenosine is more likely to yield useful information. ${ }^{18}$ A positive pharmacological stress test would select patients likely to benefit from angiography and consideration of coronary revascularisation, potentially leading to better symptom control and longer survival.

The likely net benefits from investigation and possible revascularisation should be explained to the patient, and her views sought as to whether she wishes to proceed with this or adopt a more conservative strategy.

\section{Case 3}

\section{Medical history and examination}

A 75-year-old woman is referred for assessment of weight loss of about $6 \mathrm{~kg}$ over 18 months. Her daughter explains that she has become progressively more forgetful over the previous five years. The patient's AMT score is 3/10. A chest $\mathrm{X}$-ray reveals a $2 \mathrm{~cm}$ diameter coin lesion in her right upper lobe.

Question: would you pursue bronchoscopy for this woman?

\section{Opinion}

Guidelines for investigation and treatment of a patient with suspected lung cancer emphasise the need to obtain a tissue diagnosis via bronchoscopy or percutaneous biopsy before going on to stage the disease. ${ }^{19}$ Following investigation, the most appropriate treatment can then be planned in the form of surgery, chemotherapy or radiotherapy. However, the problem of how to investigate patients with suspected lung cancer and significant comorbidity is not addressed by most guidelines.

This patient's main problem appears to be her cognitive impairment, not the lesion on the chest X-ray. With the long duration of her memory loss and current poor performance on cognitive testing, it is likely that her life expectancy will be markedly reduced because of her dementia. Late-stage dementias are often associated with weight loss, partly related to reduced food intake. This lady's cognitive impairment may be the primary cause of, or a contributor to, this symptom.

\section{Plan}

The emphasis here should be on assessment and investigation of the primary problem, the cognitive decline. Management will focus on symptom control, maintenance of level of function and organisation of social support, rather than on achieving a cure for any coexistent cancer.

However, if the patient were to develop convincing symptoms primarily related to possible bronchial carcinoma (eg recurrent haemoptysis or chest wall pain), bronchoscopy or CT scan of chest would need to be considered to confirm the diagnosis and enable more secure planning of palliative treatment (eg radiotherapy).

Although the patient is cognitively impaired and unable to give fully informed consent, her capacity to understand the above decisions should be explored. Her ability to understand the issues is likely to be very limited, and more detailed explanations and discussions will be required with her next-of-kin. If she develops complications and further assessment is contemplated, it is important to determine whether she will accept investigation. If she is resistant, this should be respected and empirical palliative treatment offered instead. If she is amenable to investigation, and this decision is supported by her family, the diagnostic test least likely to cause the patient any upset should be chosen. A CT scan of the chest may be preferable to bronchoscopy.

\section{Conclusions}

The three scenarios above highlight some of the difficulties in decision-making that can occur when planning investigation of older patients. Proper planning requires identification of major $\mathrm{Co}^{-}$ morbidities, and prioritisation of their importance in causing symptoms, affecting QoL and in determining life expectancy. Cognitive impairment and disability become increasingly common with advancing age and play a major role in determining QoL. Determination of cognitive function and the severity of any disability should be a routine part of clinical assessment.

The views of the older patient are vital in informing the plan of investigation. Automatic ordering of investigations that will not benefit the patient is inappropriate. However, discrimination against older patients by restricting access to key investigations is also unacceptable. Where a decision is taken not to investigate, the rationale for this should be made explicit and clearly documented.

\section{References}

1 Parker CJ, Morgan K, Dewey ME. Physical illness and disability among elderly people in England and Wales: the Medical Research 
Council Cognitive Function and Ageing Study. J Epidemiol Community Health 1997; 51:494-501.

2 Abrams M. Beyond three-score and ten: a first report on a survey of the elderly. Mitcham: Age Concern, 1978.

3 Graham JE, Rockwood K, Beattie BL, Eastwood R et al. Prevalence and severity of cognitive impairment with and without dementia in an elderly population. Lancet 1997;349:1793-6.

4 Barclay LL, Zemcov A, Blass JP, Sansone J. Survival in Alzheimer's disease and vascular dementias. Neurology 1985;35:834-40; erratum 36:1009.

5 Erkinjuntti T, Ostbye T, Steenhuis R, Hachinski V. The effect of different diagnostic criteria on the prevalence of dementia. N Engl J Med 1997;337:1667-74.

6 Inouye SK. Delirium in hospitalized older patients: recognition and risk factors. $J$ Geriatr Psychiatry Neurol 1998;11:118-25; discussion 157-8.

7 Harwood DM, Hope T, Jacoby R. Cognitive impairment in medical inpatients. II: Do physicians miss cognitive impairment? Age Ageing 1997;26:37-9.

8 Hodkinson HM. Evaluation of a mental test score for assessment of mental impairment in the elderly. Age Ageing 1972;1:233-8.

9 Folstein MF, Folstein SE, McHugh PR. 'Mini-mental state'. A practical method for grading the cognitive state of patients for the clinician. J Psychiatr Res 1975;12: 189-98.

10 Melzer D, McWilliams B, Brayne C, Johnston T, Bond J. Profile of disability in elderly people: estimates from a longitudinal population study. BMJ 1999;318: 1108-11.

11 Mahoney FI, Barthel D. Functional evaluation: the Barthel index. Maryland State Med J 1965;14:61-5.

12 Ditto PH, Druley JA, Moore KA, Danks JH, Smucker WD. Fates worse than death: the role of valued life activities in health-state evaluations. Health Psychol 1996;15:332-43.

13 Patrick DL, Starks HE, Cain KC, Uhlmann RF, Pearlman RA. Measuring preferences for health states worse than death. Med Decis Making 1994;14:9-18.

14 Bamford J. Clinical examination in diagnosis and subclassification of stroke. Lancet 1992;339:400-2.

15 Willoughby JM, Laitner SM. Audit of the investigation of iron deficiency anaemia in a district general hospital, with sample guidelines for future practice. Postgrad Med J 2000;76:218-22.

16 Bowling A. Ageism in cardiology. Review. BMJ 1999;319:1353-5.

17 SIGN guideline 32. Coronary revascularisation in the management of stable angina pectoris. www.sign.ac.uk/guidelines, 1998.

18 Schulman SP, Fleg JL. Stress testing for coronary artery disease in the elderly. Review. Clin Geriatr Med 1996;12:101-19.
19 SIGN guidelines. Management of lung cancer. www.sign.ac.uk/guidelines, 1998; no 23.

\section{SELF-ASSESSMENT QUESTIONNAIRE}

\section{Elderly Medicine}

Ten self-assessment questions (SAQs) based on the published articles will appear at the end of each CME specialty featured in Clinical Medicine. The questions have been validated for the purpose of CME by independent experts. Two (2) CME credits will be awarded to those achieving $80 \%$ correct answers. This opportunity is open only to RCP Fellows and Collegiate Members in the UK who are registered for CME*.

A loose leaf answer sheet is enclosed, which will be marked electronically at the Royal College of Physicians. Answer sheets must be returned by 21 November 2003 to:

CME Department (SAQs), Royal College of Physicians,

11 St Andrews Place, London NW1 4LE.

Overseas members only can fax their answers to 02074874156

Correct answers will be published in the next issue of Clinical Medicine.

*Further details on CME are available from the CME department at the Royal College of Physicians (address above or telephone 02079351174 extension 306 or 309).

\section{Guidelines on completing the answer sheet}

Your completed answer sheet will be scanned to enable a quick and accurate analysis of results. To aid this process, please keep the following in mind:

1 Please print your GMC Number firmly and neatly

2 Only write in allocated areas on the form

3 Only use pens with black or dark blue ink

4 For optimum accuracy, ensure printed numbers avoid contact with box edges

5 Please shade circles like this: Not like this:

6 Please mark any mistakes made like this:

7 Please do not mark any of the black squares on the corners of each page

8 Please fill in your full name and address on the back of the answer sheet in the space provided; this will be used to mail the form back to you after marking. 